This item was submitted to Loughborough's Research Repository by the author.

Items in Figshare are protected by copyright, with all rights reserved, unless otherwise indicated.

\title{
The role of physical activity/sport in tackling youth disaffection and anti-social
} behaviour

PLEASE CITE THE PUBLISHED VERSION

http://dx.doi.org/10.1080/00131910802393464

PUBLISHER

Taylor \& Francis (Routledge) @ Educational Review

VERSION

AM (Accepted Manuscript)

LICENCE

CC BY-NC-ND 4.0

\section{REPOSITORY RECORD}

Sandford, Rachel A., Rebecca Duncombe, and Kathleen Armour. 2019. "The Role of Physical Activity/sport in Tackling Youth Disaffection and Anti-social Behaviour”. figshare. https://hdl.handle.net/2134/15184. 
This item was submitted to Loughborough's Institutional Repository (https://dspace.lboro.ac.uk/) by the author and is made available under the following Creative Commons Licence conditions.

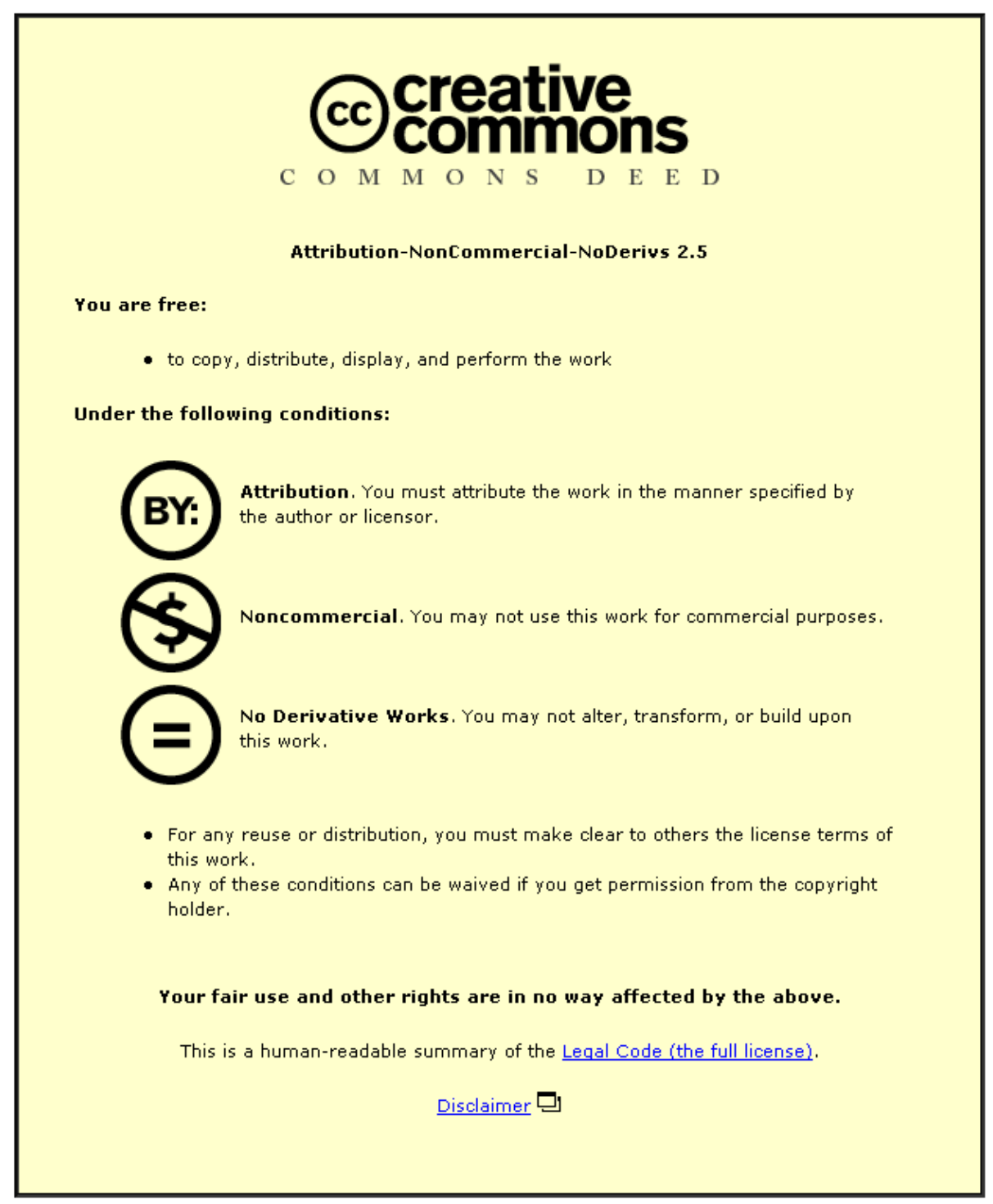

For the full text of this licence, please go to: http://creativecommons.org/licenses/by-nc-nd/2.5/ 


\title{
The role of physical activity/sport in tackling youth disaffection and anti-social
}

\section{behaviour}

\author{
R.A. Sandford, R. Duncombe and K.M. Armour \\ School of Sport and Exercise Sciences, Loughborough University, UK
}

\begin{abstract}
The purpose of this paper is to consider new and existing evidence about the impact of sport/physical activity programmes on positive youth development in the context of education. The issue of youth disaffection is topical (Davies, 2005) and a number of authors and policy makers have acknowledged that physical activity/sport may be an effective way of helping to address the problem (e.g. Sandford, Armour \& Duncombe, 2007). As a result, a number of initiatives aimed at re-engaging disaffected or disadvantaged young people through physical activities have been developed and implemented in schools in the UK. Two such initiatives, the HSBC/Outward Bound project and Youth Sport Trust/BSkyB 'Living For Sport' programme, are discussed within this paper, and key findings from the monitoring and evaluation of each initiative are presented. Over a period of 3 years, more than 7000 pupils have been engaged in these programmes, and complete data sets have been collated for over 50\% and 90\% of Sky Living For Sport and HSBC/Outward Bound participants respectively. The findings suggest that both of these projects have had a positive impact on the behaviour and attendance of large numbers of pupils, and that engagement in lessons and relationships with both teachers and peers have improved and can be sustained. The findings also demonstrate, however, that impact is highly individualised and context-specific in many cases, and that positive impact is more likely to be sustained when some or all of the following project features are in place: effective matching of pupil needs with the specific project objectives; locating
\end{abstract}


project activities outside of the 'normal' school context; working closely with pupils to choose activities, set targets and review progress; establishing positive relationships between project leaders / supporters (mentors) and pupils; and giving pupils the opportunity to work with and for others.

Key Words: Physical activity; youth disaffection; anti-social behaviour

Total word count (including references): 7007 
The role of physical activity/sport in tackling youth disaffection and anti-social

\section{behaviour}

\section{Introduction}

This paper considers the issue of youth disaffection, which may result in antisocial behaviour in secondary schools, and the role of sport/physical activity programmes in tackling it. In the UK, as in many other countries, there would appear to be growing public and political concern about the anti-social behaviour of some young people (Davies, 2005) and about the impact of this behaviour upon their own educational attainment and that of their peers (Hayden \& Blaya, 2005; Newburn \& Shiner, 2005). This concern has led to a wide range of policies and programmes that target aspects of anti-social behaviour in order to re-engage young people in the educational process (Steer, 2000; Hayes \& Stidder, 2003). In this context, sport/physical activity programmes are popular tools, based on a prevailing belief in their potential to instil positive attitudes, traits and values, and to secure a wide range of benefits for young people who are disaffected with, or disengaged from, one or more aspects of society (Martinek \& Hellison, 1997; Miller, Bredemeier \& Shields, 1997; Burt, 1998). However, while policy makers and funders appear to have faith in the value of sport/physical activity programmes, it has also been argued that there is a lack of robust, empirical evidence to support those beliefs (Long \& Sanderson, 2001; Morris et al., 2003). 
Moreover, Crabbe (2006a) has noted that attempts to establish direct causal relationships between involvement in sporting activities and social outcomes, such as reducing criminal or anti-social behaviour, are problematic. He contends that such an approach is overly simplistic, and can be viewed as 'a rather crass effort to bang square pegs into round holes' (p. 7). Indeed, a number of researchers are now suggesting that it is the nature of the process rather than the specific activity in which young people are engaged that is of real significance, and it is argued that attempts to determine effectiveness should not simply focus on outcomes alone (Bailey, 2005; Sandford, Armour \& Warmington, 2006).

Notwithstanding these concerns, physical activity, physical education and sport have featured prominently in recent government policies on youth disaffection (e.g. the Positive Futures programme, the Physical Education, School Sport and Club Links strategy (PESSCL) and elements of the New Opportunities Fund initiative) as well as in corporate-funded initiatives aimed at re-engaging disadvantaged or disaffected young people, and there would appear to be an enduring interest in the role of sport/physical activity in 'positive youth development’ (Fraser-Thomas, Côté \& Deakin, 2005; Holt, 2007). The purpose of this paper, therefore, is to examine the existing evidence on the role of sport/physical activity programmes in positive youth development within the 
context of education. An overview of existing research and government policies in this field is followed by new evidence from the evaluation of two physical activity programmes operating in UK schools that have positive youth development objectives. It is argued that data from these two studies contribute to our understanding of how and why sport/physical activity programmes do - and sometimes do not - result in benefits for disaffected young people and a reduction in anti-social behaviour in education (Sandford, Armour \& Duncombe, 2006).

\section{The impact of sport/physical activity on positive youth development}

The prominence of anti-social behaviour in contemporary public and political debate would appear to suggest that this is a growing problem among young people in the UK (Davies, 2005). Indeed, according to recent research, the UK experiences more problems with anti-social behaviour than any other country in Western Europe (ADT, 2006). In particular, there is a belief that morals and standards of behaviour have declined over recent years, and that an increasing number of young people are behaving in selfish, disrespectful and unacceptable ways. This has resulted in the UK Government's 'Respect' agenda ${ }^{1}$ and politicians' demands for increased civility and a "revolution in responsibility"

1 The Respect Task Force was established as a cross-Governmental organisation in September 2005, with the aim of tackling anti-social behaviour and promoting the positive development of community relations (see http://www.respect.gov.uk for more information). 
(BBC, 2007a). It is worth noting, of course, that anti-social behaviour is not simply a 'youth problem', and it has been argued that young people are more likely to be the victims of anti-social behaviour than the perpetrators of it (BBC, 2007b). Nonetheless, there is significant concern in contemporary society about 'problematic' behaviour among young people, and growing levels of youth disaffection and disengagement (DSS, 1999; SEU, 2000; Steer, 2000). For example, concern has been expressed about young people's participation in unhealthy or risky behaviours such as binge drinking, smoking, drug use, and under-age (and unprotected) sex, as well as their involvement in gang culture and the apparent trend for young people to both carry and use dangerous weapons (Beinert et al., 2002; Hayward \& Sharp, 2005). This seems to herald a lack of civic engagement and responsibility among the younger generation (Clennell, 2003; DfES, 2003a,b) and is mirrored in some young people's disengagement from the school system, as witnessed in truancy, school exclusions and academic underachievement (Clare, 2003; Newburn \& Shiner, 2005).

It is suggested that significant social change in recent years has contributed to youth disaffection because young people in contemporary Western society are 'faced with a more uncertain world’ (Newburn \& Shiner, 2005 p.5). In particular, altered patterns of traditional youth transitions, for example the delay in young 
people’s movement from school to work, are believed to place young people in a state of 'semi-dependence' for longer, causing some to become distanced from active engagement in social activities. Concerns about youth disaffection or disengagement have been reflected in debate across a number of fields and disciplines within both the UK and beyond (Smink, 2000; Sandford, Armour \& Warmington, 2006) and have resulted in something of a renewed moral panic concerning the threat that young people pose to social and moral order (Davies, 2005). It is worth remembering, however, that such panics about youth behaviour are not new (Pearson, 1983; Newburn \& Shiner, 2005) but the intensity of current concerns has led to a belief that 'something must be done'. A series of government measures has been put in place to tackle the problem. These include civil orders, such as Anti-Social Behaviour Orders, Acceptable Behaviour Contracts and Penalty notices; the establishment of new agencies to support/work with young people, for example Youth Inclusion Programmes, Pupil Referral Units and Youth Offending Teams, and the provision of alternative educational curricula, such as the CoPE qualification and the SEAL initiative ${ }^{2}$. In addition, a series of projects and initiatives have been introduced that are designed to re-engage disaffected,

2 The Certificate of Personal Effectiveness (CoPE) is a GCSE equivalent qualification, developed by the educational charity ASDAN (Award Scheme Development and Accreditation Network) and has recently been approved as a full qualification by the QCA (Qualifications and Curriculum Authority). The SEAL programme (Social and Emotional Aspects of Learning) is a DfES curriculum resource that aims to develop the qualities and skills that help promote positive behaviour and effective learning. 
disadvantaged or disengaged young people; for example Positive Futures, the Connexions service and elements of the National Lottery New Opportunities Fund. Most of these measures are grounded in a belief in the need for a multi-agency approach to tackling social problems (Merton \& Parrott, 1999; Kraft \& Wheeler, 2002; Martin, Fraser \& Sweetman, 2005). Thus, the intention is that these interventions are embedded in a network of key relationships that involve community agencies, local authorities, educational institutions and young people themselves.

Around the world, there is evidence of sport/physical activity programmes being used to re-engage young people in education and society more broadly (Sandford, Armour \& Duncombe, 2006). For example, within the UK, initiatives such as 'Positive Futures', the Youth Sport Trust/BSkyB 'Living For Sport' and the HSBC/Outward Bound project are all focussed on using physical activities to enhance personal development. In the US, programmes such as 'Teaching Personal and Social Responsibility’ (Hellison, 1995), ‘Sport Education’ (Siedentop, 1994) and 'Sport for Peace' (Ennis, 1999) are grounded in similar principles. Clearly, in this context, school Physical Education (PE) programmes can be particularly beneficial as they have the potential to reach all young people (Bailey, 2005). There are certainly claims made in the physical education research literature about 
different forms of positive youth development that can be achieved through physical activity, PE and school sport, and strong theoretical foundations for such approaches have been developed (Burt, 1998; Lawson, 1995, 1997). In particular, it has been argued that engagement in physical activities can help to: enhance an individual's confidence and sense of self-worth (Nichols, 1997); promote the capacity for collaborative work (Priest \& Gass, 1997); facilitate positive sociomoral development (Danish, 2002; Larson \& Silverman, 2005); instil a sense of personal and social responsibility (Hellison, 1995; Lawson, 1999; Martinek, Schilling \& Hellison, 2006); and help to address problems of disadvantage and social exclusion through the generation of social capital (Bailey, 2005; Crabbe, 2006a). Such is the conviction that involvement in physical activities can help to address social concerns and contribute to positive personal development, that it has resulted in what Pitter and Andrews (1997) defined as a 'social problems industry' (p.85) in which numerous public and privately sponsored initiatives (such as those outlined later in the paper) are being developed.

Although there is some ambivalence in the literature about the precise mechanisms by which sport/physical activity leads to positive youth development, there are also some areas of agreement. For example, it is widely agreed that just as in other interventions, sport/physical activity programmes should be embedded in a multi- 
agency approach and focussed specifically on building positive relationships among all parties (Cameron \& MacDougall, 2000; Martin, Fraser \& Sweetman, 2005; Crabbe, 2006a). There is now a clear understanding that whereas the sport/physical activity context itself has the potential to deliver positive outcomes, it is the social processes inherent within programmes, and the explicit focus on personal development, that are most significant in effecting behavioural change (Long \& Sanderson, 2001; Sandford, Armour \& Warmington, 2006; Crabbe, 2006a). This understanding has implications for the development, delivery and leadership of any programmes or initiatives designed to re-engage disaffected youth and improve behaviour. In particular, a number of studies have highlighted the need for the adults involved in such programmes to possess characteristics that will facilitate positive relationships; e.g. credibility, fairness, consistency and respect (Riley \& Rustique-Forrester, 2002; Wilson \& White, 2001) and there is further evidence to support this claim in the literature on youth mentoring and informal education (Reid, 2002; Ellis, 2003; Richardson \& Wolfe, 2001).

In summary, literature in the field of sport/physical activity and its impact on disaffected young people in education would suggest that there is a prevailing belief in the ability of sport, physical activity and physical education to bring about positive youth development. There is some limited evidence that these activities 
can 'work' although, as mentioned, the processes by which this happens are not well documented. In order to provide stronger evidence, therefore, robust, empirical evidence is required (Long \& Sanderson, 2001; Morris et al., 2003) and it is generally agreed that systematic, longitudinal evaluation research is needed in order to test the accuracy of these claims (Sandford, Armour \& Duncombe, 2006). Nonetheless, it is evident that both contemporary and historical education policy is underpinned by prevailing beliefs about the efficacy of sport/physical activity in offering wider educational benefits to young people.

An overview of policy relating to sport/physical activity and positive youth development

The belief in a link between engagement in sport/physical activity and positive youth development outcomes can be traced throughout history. For example, the notion of 'mens sana in corpore sano' was prevalent within ancient Egyptian, Greek and Roman history, while the philosophy of Muscular Christianity, with its focus on sport/physical activity as character building, was very much evident within 19th century England (Sandford, Armour \& Warmington, 2006). More recently, a series of government Education Acts and Reports have reinforced the link between sport/physical activity and socio-moral development. These included the Acts of 1944 and 1988, the Warnock (1978) and Elton (1989) Reports, and the 
National Curriculum for England and Wales which identified opportunities for spiritual, moral, social and cultural development through physical education (DfEE/QCA, 1999). Furthermore, from the late 1990s onwards sport/physical activity for young people has emerged as one of the central policy themes within the government's wider social inclusion agenda (DCMS, 2002; Flintoff, 2003). Indeed, a recent government report (DCMS, 2007) highlights the significance of physical education and school sport in tackling youth disaffection in schools and improving attendance, behaviour and pupils’ educational attainment:

'Physical education and school sport are important in raising standards and narrowing the achievement gap. The Qualifications and Curriculum Authority has shown how putting PE and School Sport at the heart of a broad and balanced Curriculum can improve attendance, behaviour and attainment. Physical Education and Sport build self-esteem, teamwork and leadership skills. They can also help build an inclusive society, raise levels of participation in sport after pupils leave school and positively affect the health of the nation...' (p.45)

Perhaps the clearest evidence of governmental faith in the benefits of sport/physical activity for young people is the scale of public funding supporting the PESSCL strategy. The PESSCL strategy was launched by former Prime Minister Tony Blair in October 2002 and, together with lottery funding, has resulted in over $£ 1.5$ billion being invested in physical education and school sport (PESS) running up to 2008. The ambitious target of the PESSCL strategy is to increase the percentage of schoolchildren who spend a minimum of two hours a 
week on high-quality PESS, within and beyond the curriculum, to 85\% by 2008 . The longer term ambition (by 2010) is to offer all children at least four hours of PESS every week. Two of the strands of the PESSCL strategy (School Sports Partnerships and Sports Colleges) are linked closely to the delivery of the Government’s wider 'Every Child Matters’ (ECM) agenda. The overriding vision of ECM is for:

'Every child, whatever their background or their circumstances, to have the support they need to: be healthy; stay safe; enjoy and achieve; make a positive contribution; (and) achieve economic well-being' (DCSF, 2005).

Through the development of 'children and young people plans', local authorities are tasked with delivering a series of outcomes for young people, some of which will involve extended school provision to support children and young people’s well-being, particularly those who are disadvantaged or excluded from the mainstream in some way (Aynsley-Green, 2006). School Sports Partnerships, for example, are likely to be pivotal in offering physical activity opportunities to young people within extended school provision, thus contributing to one element of the broad 'health' element of the ECM agenda. Yet physical education researchers have raised important questions about the role of sport/physical activity in meeting the needs of disengaged, disaffected or disadvantaged young people. Houlihan \& Green (2006), for example, question the capacity of local 
sports networks and partnerships to deliver broad social inclusion agendas, and a series of researchers have argued that the sport/physical activity environment can be both alienating and humiliating for some young people, particularly for those with little aptitude for sport (Williams and Bedward, 2001; Flintoff and Scraton, 2001; Sandford, Armour \& Warmington, 2006).

Summarising the available evidence to date, it can be argued that government policies, both past and present, have reflected a consistent belief in the positive youth development benefits that can be accrued from involvement in sport / physical education / physical activity. However, this belief appears to have been based on little robust research evidence. The purpose of this paper, therefore, is to present evaluation evidence from two longitudinal research projects, which have specifically examined whether and how short and longer term positive youth development outcomes result from participation in physical activity programmes. Both programmes are corporate-sponsored interventions that have the core purpose of using different forms of physical activity to re-engage disaffected young people in the school context and, in the case of one programme in particular, to reduce anti-social behaviour. 


\section{Overview of the programmes}

The HSBC/Outward Bound (HSBC/OB) and Youth Sport Trust/BSkyB 'Living for Sport' (Sky Living For Sport) projects are corporate-sponsored initiatives that aim to use physical activity to re-engage disaffected young people in the school context. The HSBC/OB project is a 5-year programme that funds residential outdoor/adventurous activity experiences for pupils from five schools in the Docklands area of London (the location of HSBC's UK head office). Each year, a cohort of 30 young people from Year 9 in each school (total 150) is selected to take part in an organised programme of activities that span a whole school year. These activity sessions are designed to provide individual and group challenges and to develop skills such as team building, communication, and responsibility. A number of HSBC staff are involved in the project each year as volunteer mentors, and are trained to work with schools and pupils both within the project activity sessions and in follow-up activities within the schools ${ }^{3}$. The Sky Living For Sport project, on the other hand, is a national initiative that encourages schools to run their own projects within a broad framework developed by the project sponsors and organisers. Teachers organising Sky Living For Sport projects within their schools can select any activity, or combination of activities, for pupils and these

\footnotetext{
${ }^{3}$ Further information concerning the HSBC/Outward Bound project can be found at: http://www.lboro.ac.uk/departments/sses/institutes/iys/pages/Research/ResearchInclusion/outwardb ound.html
} 
have included climbing, abseiling, horse-riding, skiing, tennis, football, martial arts, aerobics and circus skills. Sky Living For Sport projects can last from one term to one academic year and project sizes vary from 4-75 pupils, although groups of 8-16 pupils are most common. Each Sky Living For Sport project culminates in a sport event, which is often a tournament or competition organised by the project pupils, and completion of the 'course' is marked by a celebration event such as a party, a meal at a restaurant, a trip to a theme park, an evening of bowling or a barbeque ${ }^{4}$. Although the projects are different in some aspects, they share key features that are relevant to the discussion in this paper; i.e. project aims, pupil selection by teachers, and school 'ownership' of the projects (within broad guidelines).

\section{Research Methods}

Over the past three years, over 7000 pupils have been involved in the HSBC/OB and Sky Living For Sport projects, with approximately 4600 pupils currently engaged in ongoing activities. The number of pupils involved in each year of the projects is shown in the table below (Table 1 ).

[Insert Table 1]

${ }^{4}$ Further information concerning the YST/BSkyB 'Living for Sport' project can be found at: http://www.lboro.ac.uk/departments/sses/institutes/iys/pages/Research/ResearchInclusion/livingfors port.html 
In summary, at the heart of the multi-layered research strategy for each project is the generation of individual pupil profile information that is collected pre and post involvement in project activities. This approach takes into account the need for individual baseline data in order to determine impact (Long et al., 2002). Profile data are generated through survey-style feedback sheets, administered to teachers, and they include a combination of open-ended questions and ratings scales. Based on the reason given (by teachers) for pupil selection, teachers are asked to use school data and/or their professional judgement to provide information on each pupil's current status, for example in attendance, behaviour or perceived levels of self-esteem / confidence. These profiles are then updated at intervals throughout the projects in order to determine the 'distance travelled' by each individual pupil (DfEE, 2000; Crabbe, 2006b). It should be noted that the findings presented in this paper are drawn only from complete data sets i.e. where both baseline and update data have been received for individual pupils. These data relate to approximately $50 \%$ of all Sky Living For Sport pupils engaged in the project nationally, and approximately $90 \%$ of $\mathrm{HSBC} / \mathrm{OB}$ pupils from the five participating schools. In both projects, individual interviews and focus group discussions with teachers and pupils have also been used, in addition to the feedback sheets, to create in-depth case study profiles of both schools and participants. 


\section{Findings 1 - Short term impact}

Although there are variations in the data from the HSBC/OB and Sky Living For Sport projects, the broad findings regarding the nature of project impact are remarkably similar. Specific project data, case study reports and detailed short term impact data have been presented elsewhere (Armour \& Bowyer, 2004; Duncombe \& Armour, 2005; Eades, Armour, Duncombe \& Pearson, 2006; Armour, Duncombe \& Stewart, 2007, Sandford, Armour \& Duncombe, 2006; Sandford, Armour \& Duncombe, 2007). The aim of this discussion, therefore, is to summarise these findings, highlight the potential for longer term impact and identify some of the factors that appear to lead to positive and sustained project impact. As such, the paper goes some way towards addressing the need for research to focus on the processes that lead to positive impact rather than simply identifying the product of participation (Bailey, 2005; Sandford, Armour \& Duncombe, 2006; Sandford, Armour \& Warmington, 2006).

In broad terms, data from Years 1 to 3 from both projects indicate that many pupils improve from their baseline profiles after project involvement. Data from Years 2 and 3 of Sky Living For Sport, for example, show (using school-recorded statistics) that there is a slight increase in participating pupils' mean attendance 
Educational Review Vol. No. Month 200, 000-000

Special Issue: Truancy, Disaffection, Anti-Social Behaviour and the Governance of Children

rates and a decrease in the number of behavioural referrals (see Table 2). Similarly, for those pupils where no specific baseline statistics were available, teachers' perceptions were of improvements in pupils’ behaviour, attendance rates and levels of self-esteem as a result of participation in Sky Living For Sport projects (see Table 3).

[Insert Table 2]

[Insert Table 3]

For the HSBC/OB project, data from Years 1 to 3 show that the percentage of pupils who are perceived to show positive improvements from their baseline profiles (six months after starting project activities) is, on the whole, greater than those who show no change or drop below baseline. Indeed, where data are available, project group pupils also appear to outperform a comparison group of pupils who did not participate in project activities ${ }^{5}$ (see Table 4). In addition to these indicators, qualitative data generated through interviews with teachers in

${ }^{5}$ Pupils in the comparison group were matched, by teachers, to include the same range of characteristics they had used to select project pupils; for example low self-confidence, disruptive behaviour or poor communication skills. The aim was to create a comparison group of 10 pupils that had a similar profile to the project group. This was not an ideal method of creating a comparison group, given that the project group consisted of 30 pupils. However, it was found to be the only workable method given that a) each teacher had complete freedom to select project pupils based on their perception of who would 'benefit' from the project in some way and b) teachers simply did not have to time to identify or track an additional group of 30 pupils each year. 
both projects have highlighted a number of specific benefits for pupils. In particular, teachers have noted that, as a result of project involvement, the majority of pupils: are happier within school and appear more engaged within lessons; are less disruptive in large group situations and more able to work with others; experience better relationships with both their peers and school staff; show improved levels of personal confidence (e.g. to speak out in class, to give presentations or to get involved in other activities/initiatives); and (in a small number of cases) experience an improvement in academic performance.

[Insert Table 4]

It should be noted, however, that data from both HSBC/OB and Sky Living For Sport also indicate that not all pupils benefit from the projects, and that the impact of project activities is often highly individualised, context specific and, for some individuals, short-lived. For example, teachers from Sky Living For Sport schools have commented that, whereas pupils' attendance levels may improve for project activities, this does not necessarily translate into improved attendance across the school, and there are several examples from the HSBC/OB project of different teachers providing conflicting reports about the progress of the same pupil. The 
following comments, relating to the progress of a year 1 pupil named Kyle, provide an illustration of this:

'Kyle is still very aggressive and confrontational' (feedback from Form Tutor at 6 months)

'(Kyle) is more responsible about listening whilst I am talking to the class, (and) although he has a bit of a bad temper, he is getting better at controlling it' (feedback from classroom teacher at 6 months)

\section{Findings 2 : Longer term impact}

Concerns over the potential for initiatives such as these to effect a lasting impact on young people's personal development are well established in the physical activity literature (e.g. Morris et al., 2003; Sandford, Armour \& Warmington, 2006). The early evaluation of the Sky Living For Sport programme focused solely on initial impact, however, in response to these concerns research conducted over the last two years has sought to identify sustained impact. The data available for this aspect of the research is limited (when compared to the short-term impact data) and there are a number of reasons for this: pupils left the school; schools stopped running projects (and, therefore, did not get sent the forms); forms were incorrectly completed; and not all schools returned their forms. For example, of the 32 schools that participated in the first year of the project, 19 of these participated in the second year and only 7 returned their forms. The following table 
shows the number of these pupils identified (by teachers) as showing initial improvements and the number who maintained these improvements for approximately 12 months (see Table 5). Data from the HSBC/OB project also indicate that many (although not all) pupils maintain positive improvements beyond the life of the initiative, as the following table (Table 6) outlining the progress of Year 1 pupils illustrates.

[Insert Table 5]

[Insert Table 6]

These findings can be regarded as promising, particularly in the case of the Sky Living For Sport project. However, what is particularly interesting for the purposes of this paper are the data on the characteristics of projects that appear most likely to lead to sustained positive impact.

\section{Findings 3: effective project features}

The above two sections highlight that structured projects using physical activity and sport to re-engage young people can be successful in that they can 'work' in different ways for young people with a wide range of 'needs'. While the variables in these projects are numerous (organisation, schools, pupil selection, activities 
etc.) it is clear that where projects are successful, some or all of the following features are in place:

- effective matching of pupil needs with the specific project objectives;

- locating project activities outside of the 'normal' school context;

- working closely with pupils to empower them to choose activities, set targets and review progress;

- establishing positive relationships between project leaders / supporters (mentors) and pupils (and, importantly, providing some scope for these to continue outside of project activities);

- and giving pupils the opportunity to work with others and, more particularly, for the benefit of others.

Teachers from both projects were also asked, both through interviews and feedback sheets, to identify what may have helped the young people to maintain positive improvements. In each case, the issue of sustained project involvement was highlighted. Findings from the HSBC/OB project indicate that the young people who are selected to progress to the latter stages of the project (i.e. the weekend residential and three-week residential events) are more likely to maintain an improvement from baseline than those who do not. For example, after 24 months, for those pupils in Year 2 of the project who attended not only the initial 
residential week of activities but also the follow-up weekend, the mean percentage showing positive improvements from baseline was $74 \%$, compared to a whole group mean of 61\%. In addition, teachers from both the HSBC/OB and Sky Living For Sport projects indicated that many of the pupils who show a positive improvement from baseline after the initial project year has ended are those who continue with involvement in other programmes or initiatives (e.g. the Duke of Edinburgh Award Scheme, Young Enterprise and business mentoring schemes). Other possible factors that may contribute to sustained improvements, as identified by Sky Living For Sport teachers through an end of project postal survey (Years 1 and 2), are illustrated in the table below (Table 7).

[Insert Table 7]

Interestingly, many of these findings echo suggestions made in the existing literature on youth physical activity programmes (see Hellison, 1995; Ennis 1999; Sandford, Armour \& Warmington, 2006) and highlight the significance of social processes. For example, Donnelly and Coakley (2002) have stressed the importance of sport/physical activity programmes fostering a sense of belonging and acceptance, and this factor was supported strongly by teachers in both the HSBC/Outward Bound and Sky Living For Sport projects. In other words, whereas 
sport and physical activity were used as a vehicle for both projects reported in this paper, it is clear that success was not an inherent feature of the activities themselves; rather it was achieved where a series of other factors were in place (see earlier list). Moreover, social interaction and the establishment of positive relationships amongst pupils and between pupils and adults are key factors within this process.

As is reported in the wider education and physical education literature (e.g. Golden, Lines \& Sims, 2002; Martinek \& Hellison, 1997) it is evident from all the findings reported in this paper that the suitability of the adults involved in delivering projects and supporting pupils cannot be underestimated. In these two projects, adult involvement centred on volunteers (mentors in the HSBC project) and teachers (both projects). It has been argued that project leaders who are charismatic, respectful and willing to tackle issues associated with disaffection are more likely to effect positive change in the lives of the young people with whom they work (Nichols, 1997; DCMS, 1999; Steer, 2000). Certainly, within the HSBC/Outward Bound and Sky Living For Sport projects, pupils reported positive experiences where they had found the teachers/mentors to be supportive, helpful and encouraging, with some suggesting that they had enjoyed getting to know project adults over time (see also Sandford \& Armour, 2006; Armour, Duncombe 
and Stewart, 2007). However, feedback from these projects also highlights the importance of careful planning with regard to the selection and training of volunteers, as well as the need for a system of support to facilitate their ongoing role within the project. Bearing in mind the significance of social relationships, as noted above, the need to prepare and train adults specifically to maximise positive youth development outcomes from physical activity/sport settings is clearly intimated.

\section{Conclusion}

It is clear from government policies over the last 20 years that there is a strong and enduring belief that engaging in physical activity/sport programmes is 'good' for young people who are showing signs of disaffection and anti-social behaviour. It is also clear from the existing research in this area that whereas the physical activity/sport context is promising in this regard, there are myriad factors involved in maximising the potential of that context. The evidence presented in this paper would appear to endorse these findings, in particular through highlighting the potential for positive and sustained improvements for pupils as well as the project features that can help, or hinder, this impact. Moreover, the significance of establishing and maintaining positive social relationships between young people and programme leaders/volunteers would appear to be central to this process and a 
key feature in maximising the impact of sport/physical activity initiatives on positive youth development. This seems to suggest that, if physical education teachers and youth sport coaches are to make an impact upon disaffected youth then they should be offered professional development on the factors identified in this research that are most likely to lead to improvements. Currently, within the national professional development programme for PE teachers or in governing body coaching awards for sports coaches, there is virtually no such provision available. 


\section{References}

ADT Europe. 2006. Anti-Social Behaviour Across Europe. An overview of research commissioned by ADT Europe. ADT Fire and Security PLC.

http://www.adt.co.uk/antisocial.html.

Armour, K. M. \& Bowyer, S. 2004. YST / BSkyB 'Living for Sport' Programme: End of phase 1 report. Loughborough: Institute of Youth Sport.

Armour, K.M. \& Sandford, R.A. 2004. Evaluation of the HSBC / Outward Bound Project: interim report, 12 months. Loughborough: Institute of Youth Sport.

Armour, K.M. \& Sandford, R.A. 2004. Evaluation of the HSBC/Outward Bound Project: interim report, 18 months. Loughborough: Institute of Youth Sport.

Armour, K.M., Duncombe, R. \& Stewart, K. 2007. Combined report for years 1-3 of YST/BSkyB 'Living for Sport'. Loughborough: Institute of Youth Sport.

Aynsley-Green, A. 2006. Office of the Children's Commissioner annual report and accounts 2005/2006. London: The Stationery Office.

Bailey, R. 2005. Evaluating the relationship between physical education, sport and social inclusion. Educational Review 57, no.1: 71-90.

Beinart, S., Anderson, B., Lee, S. \& Utting, D. 2002. Youth at risk? A national survey of risk factors, protective factors and problem behaviour among young people in England, Scotland and Wales. London: Communities that Care.

BBC (British Broadcasting Corporation). 2007a. Cameron civic responsibility push. BBC website. http://news.bbc.co.uk/1/hi/ik_politics/6582423.stm.

BBC (British Broadcasting Corporation). 2007b. Constructive activities for children and young people. Respect website.

http://www.respect.gov.uk/members/article.aspx?id=9790.

Burt, J.J. 1998. The role of kinesiology in elevating modern society. Quest, no.50: 80-95.

Cameron, M., \& MacDougall, C. 2000. Crime Prevention Through Sport and Physical Activity, no.165: 1-6.

Clare, J. 2003. Schools failing 80,00 teenage pupils a year. BBC website. http://www.telegraph.co.uk/education/main.

Clennell, A. 2003. Truancy project has had no impact. Independent News and Media Ltd. http://www.education.independent.co.uk/news/story.jsp?story=410001.

Condon, J. \& Smith, N. 2003. Prevalence of drug use: findings from the 2002/2003 British Crime Survey. London: Home Office.

Crabbe, T. 2006a. Knowing the score, Positive Futures case study research: final report. London: Home Office.

Crabbe, T. 2006b. Going the distance: impact, journeys and distance travelled (third interim national Positive Futures case study research report). Positive Futures. http://www.positivefuturesresearch.org.uk.

Danish, S. J. 2002. Teaching life skills through sport. In Paradoxes of youth and sport, ed. M. Gatz, M. A. Messner \& S. J. Ball-Rokeach. 49-59. Albany, NY: State University of New York Press. 
Davies, B. 2005. Threatening youth revisited: youth policies under New Labour. The encyclopaedia of informal education.

http://www.infed.org/archives/bernard_davies/revisiting_threatening_youth.ht $\underline{\mathrm{ml}}$.

DCMS (Department for Culture, Media and Sport). 1999. Policy Action Team 10: report to the Social Exclusion Unit-Arts and Sport. London: HMSO.

DCMS (Department for Culture Media and Sport). 2002. Game plan: a strategy for delivering government's sport and physical activity objectives. Sport Development website. http://www.sportdevelopment.org.uk/html/gameplan.html.

DCMS / DfES (Department for Culture, Media and Sport / Department for Education and Skills). 2007. Departmental report. Norwich: HMSO.

DCSF (Department for Children, Schools and Families). 2005. Every Child Matters: aims and outcomes. Department for Children, Schools and Families.

http://www.everychildmatters.gov.uk/aims.

DfEE / QCA (Department for Education and Employment/Qualifications and Curriculum Authority). 1999. Physical education: the National Curriculum for England. London: QCA.

DfEE (Department for Education and Employment). 2000. How to evaluate education initiatives: a guide for schools. Nottingham: DfEE Publications.

DfES (Department for Education and Skills). 2003a. Permanent exclusions from schools and exclusion appeals, England 2001/2002 Provisional (SFR 16/2003). London: National Statistics.

DfES (Department for Education and Skills). 2003b. Pupil absence in schools in England 2002/3 Revised (SFR 34/2003). London: National Statistics.

DSS (Department of Social Security). 1999. Opportunity for all: tackling poverty and social exclusion. London: TSO.

Donnelly, P., \& Coakley, J. 2002. The role of recreation in promoting social inclusion. Toronto: Laidlaw Foundation.

Duncombe, R. \& Armour, K. M. 2005. YST / BSkyB 'Living for Sport'

Programme: Year 2 End of Year Report. Loughborough: Institute of Youth Sport.

Eades, J., Armour, K.M., Duncombe, R. \& Pearson, N. 2006. YST/BSkyB

'Living for Sport' Programme: End of Year 3 Report. Loughborough: Institute of Youth Sport.

Ellis, S.W. 2003. Changing the lives of children and older people: Intergenerational mentoring in secondary schools. Paper presented at the British Educational Research Association Annual Conference, September 11-13, in Edinburgh, Scotland.

Elton Report. 1989. Discipline in schools: report of the Committee of Enquiry chaired by Lord Elton. London: HMSO.

Ennis, C. D. 1999. Creating a culturally relevant curriculum for disengaged girls. Sport, Education and Society 4, no.1: 31-49.

Flintoff, A. \& Scraton, S. 2001. Stepping into active leisure? Young women's perceptions of active lifestyles and their experiences of school physical education. Sport,

Education and Society 6: 5-21. 
Flintoff, A. 2003. The School Sport Co-ordinator Programme: Changing the Role of the Physical Education Teacher? Sport, Education and Society 8, no. 2: 231-250.

Fraser-Thomas, J.L., Côté, J. \& Deakin, J. 2005. Youth sport programs: an avenue to foster positive youth development. Physical Education and Sport Pedagogy 10, no.1: $19-40$.

Golden, S., Lines, A., \& Sims, D. 2002. Mentor points: pilot year evaluation (DfES Research Report 369). London: DfES.

Hayden, C. \& Blaya, C. 2005. Children on the margins: comparing the role of school in England and France. Policy Studies 26, no.1: 67-83.

Hayes, S. \& G. Stidder. 2003. Equity and inclusion in physical education and sport. London: Routledge.

Hayward, R. \& Sharp, C. 2005. Young people, crime and anti-social behaviour: findings from the 2003 crime and justice survey (Home Office Findings no. 245). London: Home Office.

Hellison, D. 1995. Teaching responsibility through physical activity. Champaign, IL: Human Kinetics.

Holt, N. (Ed) 2007. Positive youth development through sport. London: Routledge.

Houlihan, B \& Green, M. 2006. The changing status of school sport and physical education: explaining policy change. Sport, Education and Society 11, no. 1: 73-92.

Kraft, N. P., \& Wheeler, J. W. 2002. Service-learning and resilience in disaffected youth: a research study. Paper presented at the 2nd Annual International Service-Learning Research Conference, October, in Vanderbilt University, Nashville TN.

Larson, A., \& Silverman, S.J. 2005. Rationales and practices used by caring physical education teachers. Sport, Education and Society 10, no.2: 175-194.

Lawson, H.A. 1995. International changes and challenges: Their import for new models for practice. Quest, 47, no. 4: 411-426.

Lawson, H. A. 1997. Children in crisis, the helping professions, and the social responsibilities of universities. Quest 49, no.1: 8-33.

Lawson, H.A. 1999. Education for social responsibility: preconditions in retrospect and in prospect. Quest 51, no. 2: 116-149.

Long, J. \& Sanderson, I. 2001. The social benefits of sport: where's the proof?. In Sport in the city: the role of sport in economic and social regeneration, eds. C. Gratton \& I. P. Henry, 187-203. London: Routledge.

Long, J., Welch, M., Bramham, P., Butterfield, J., Hylton, K., \& Lloyd, E. 2002. Count me in: the dimensions of social inclusion through culture, media \& sport. Leeds: Leeds Metropolitan University.

Loeber, R. \& Farrington, D.P. 2000. Young people who commit crime: epidemiology, developmental origins, risk factors, early interventions and policy implications. Development and Psychopathology 12, no.4: 737-762.

Martin, A., Fraser, J. \& Sweetman, R. 2005. Monitoring and evaluating Positive Futures, key elements: wave 6 final report. London: Home Office.

Martinek, T. J., \& Hellison, D. R. 1997. Fostering resiliency in underserved youth through physical activity. Quest 49, no.1: 34-49. 
Martinek, T., Schilling, T. \& Hellison, D. 2006. The development of compassionate and caring leadership among adolescents. Physical Education and Sport Pedagogy 11, no.2: 141-157.

Merton, B., \& Parrott, A. 1999. Only connect: successful practice in educational work with disaffected young adults. Leicester: NIACE.

Miller, S. C., Bredemeier, B. J. L., \& Shields, D. L. L. 1997. Sociomoral education through physical education with at-risk children. Quest 49, no. 1: 114-129.

Morris, L., Sallybanks, J., Willis, K., \& Makkai, T. 2003. Trends and issues in crime and criminal justice. Australian Institute of Criminology. http://www.aic.gov.au/publications/tandi/tandi249.html.

Newburn, T. \& Shiner, M. 2005. Dealing with disaffection: young people mentoring and social inclusion. London: Willan Publishing.

Nichols, G. 1997. A consideration of why active participation in sport and leisure might reduce criminal behaviour. Sport, Education and Society, 2, no. 2: 181-190.

Pearson, G. 1983. Hooligan: a history of respectable fears. Basingstoke: Macmillan.

Pitter, R., \& Andrews, D. L. 1997. Serving America's underserved youth: reflections on sport and recreation in an emerging social problems industry. Quest 49, no.1: 85-99.

Priest, S., \& Gass, M. 1997. Effective leadership in adventure programming. Champaign, IL: Human Kinetics.

Reid, K. (2002). Mentoring with disaffected pupils. Mentoring and Tutoring 10, no.2: 153-169.

Richardson, L.D., \& Wolfe, M. 2001. The principles and practice of informal education: learning through life. London: Routledge Falmer.

Riley, K. A., Rustique-Forrester, E. 2002. Working with disaffected students. London: Paul Chapman Publishing.

Sandford, R.A., Armour, K.M. \& Duncombe, R. 2006. Young people and the role of physical activity in enhancing personal/social development: evaluating sustainable impact. Paper presented at the British Educational Research Association Annual Conference, September, in September.

Sandford, R.A., Armour, K.M. \& Warmington, P.C. 2006. Re-engaging disaffected youth through physical activity programmes. British Educational Research Journal 32, no.2: 251-271.

Sandford, R., Armour, K. \& Duncombe, R. 2007. Physical activity and personal/social development for disaffected youth in the uk: in search of evidence. In Positive Youth Development through Sport, ed. N. Holt, 97-109. London: Routledge.

Siedentop, D. (Ed) 1994. Sport Education: quality PE through positive sport experiences. Champaign, IL: Human Kinetics.

Smink, J. 2000. Foreword. In Defying disaffection: how schools are winning the hearts and minds of reluctant students, $R$. Klein. Stoke on Trent, UK: Trentham Books.

SEU (Social Exclusion Unit). 2000. National strategy for neighbourhood renewal. Report of Policy Action Team 12: young people. Social Exclusion Unity website. http://www.socialexclusionunit.gov.uk/downloaddoc.asp?id=125/ 
Steer, R., 2000. A background to youth disaffection: a review of literature and evaluation findings from work with young people. London: Community Development Foundation.

Warnock Report. 1978. Special educational needs: report of the Committee of Enquiry into the education of handicapped children and young people. London: HMSO.

Williams, A. \& Bedward, J. 2001. Gender, culture and the generation gap: student and teacher perceptions of aspects of National Curriculum Physical Education. Sport, Education and Society 6, no.1: 53-66.

Wilson, B., \& White, P. 2001. Tolerance rules: identity resistance, and negotiation in an inner-city recreation/drop in center. Journal of Sport \& Social Issues 25, no.1: 73-103. 